\title{
Interlibrary Loan Policies On Dissertations and Serial Publications
}

\author{
BY JANE W. GATLIFF and SYLVIA FOREMAN
}

IN ORDER to establish a guide for making future requests, an informal survey was conducted by the Ohio State University libraries interlibrary loan service in the spring of 1963. This survey had three purposes: (1) To establish the correct date of participation of libraries which participate in the University Microfilms dissertation project; (2) To determine in general the extent of deviation from the policy of not lending dissertations available from Ann Arbor, and specifically to find out which libraries continue to lend after the date of their participation; and, (3) to learn the periodical loan policy of selected libraries.

Questionnaires were sent to 148 colleges and universities. The survey attempted to include all United States and Canadian libraries listed in the Index to American Doctoral Dissertations as participants in the University Microfilm dissertation program together with those libraries used most frequently by the OSU interlibrary loan service for periodical loans. A total of 141 replies was received, of which 138 were utilized in this report.

The results show that of the 121 libraries which cooperate in the University Microfilms project, forty-five continued to lend dissertations written after the date of beginning participation. The balance will not lend those written after the date joined. Although 115 libraries have had copies available for loan since the beginning of their doctoral programs, twentytwo have never lent theirs. ${ }^{1}$ Twenty-nine

1 These figures include libraries which do not belong to University Microfilms. Of the University Microfilms participants, 101 have had dissertations available for loan prior to the date of joining, twelve have not.
Miss Gatliff is Librarian and Miss Foreman is Library Assistant, Interlibrary Loan Service, Ohio State University.

of those that continue to lend have a microfilm copy which is sent out rather than a typed copy. In all cases the library must have two copies of the dissertation in its collection before one will be lent. Table 1 shows the dates at which institutions began participating and the loan policy on dissertations written after those dates.

Although it is difficult to generalize, it would appear that those libraries whose agreement with University Microfilms dates prior to 1953 are more willing to lend typed copies than those whose participation began in 1954 or later. Of the ninety-one libraries that began filming dissertations between the years 19541963 , twenty-five or 27.4 per cent continue to provide either a typed or film copy on loan. Of the twenty-three libraries that began filming between 19381953 , thirteen or 56.5 per cent continue to lend. The majority of libraries that participate joined University Microfilms in the eight-year span between 1952-1959.

Periodicals are still available for loan at 100 of the 138 libraries. However, of that number fifty-one will, under certain conditions, automatically (without prior notice) photocopy the material requested. Table 2 shows the distribution of libraries photocopying articles of various lengths, the criterion most often used to determine whether requests will be filled by loan or photocopy. Six libraries fur- 
TABLE 1

Dissertation Loan Policy in Relation to

DATE OF JOINING UNIVERSITY MICROFILMS, INC.

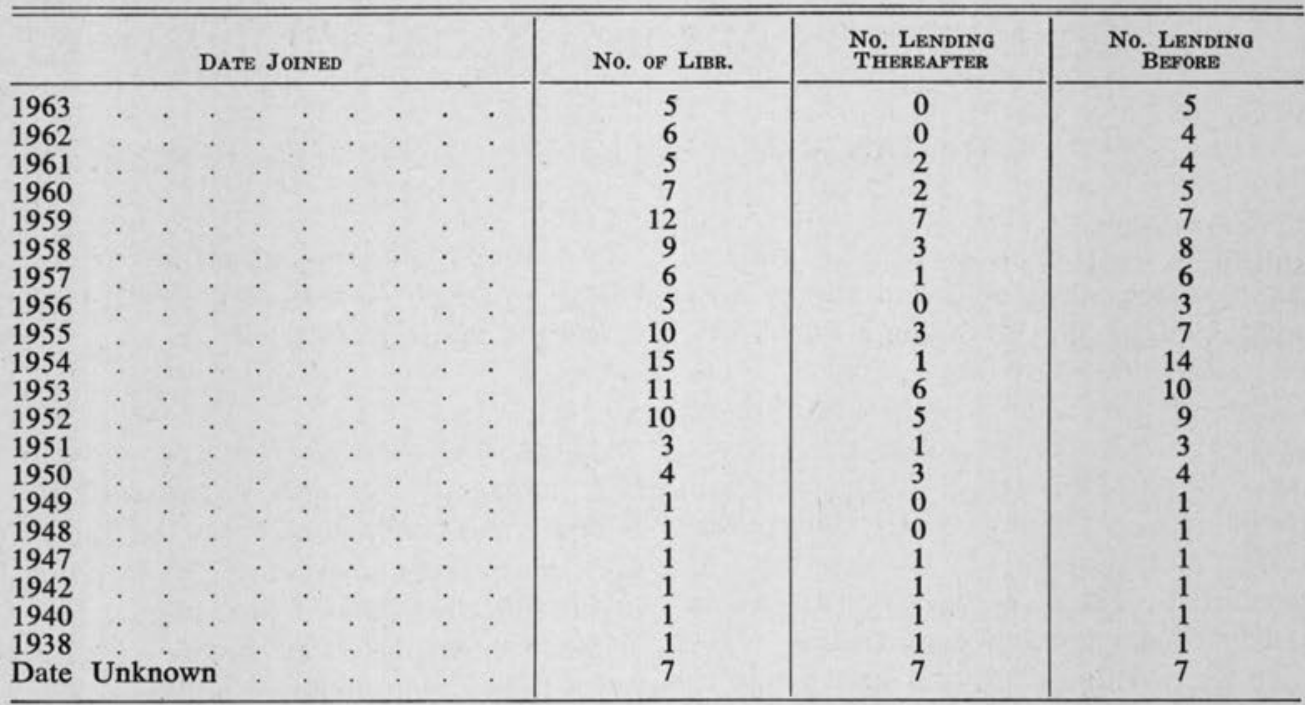

nish free photocopy. Five of those that still lend but do not automatically photocopy indicated that this policy would be changed in the near future. Thirty-eight libraries do not lend their periodicals under any circumstances, but eighteen of

TABLE 2

\section{Periodical Loan Policy and Number of Libraries Which AUtomatically Photocopy Journal Articles}

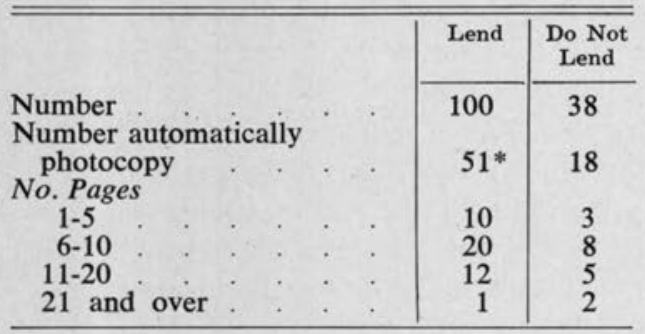

* Six libraries, one in the 1-5 pp. category and five in the 6-10 pp. eategory, indicated that they automatically photocopied only if the borrowing library had previously agreed to this policy. Two libraries failed to indicate the number of pages, although they said they automatically photocopied material. These eight libraries have been included in the total of fifty-one but do not appear in the table indicating the number of pages photocopied. these will automatically photocopy requests for articles of varying lengths.

Only twenty-four libraries out of the sixty-nine that automatically photocopy supplied detailed information on their charges and billing procedures. Sixteen libraries have minimum charges; eight do not. Five libraries have a minimum charge of $\$ .50$, seven have $\$ 1.00$, and three libraries reported minimums ranging from $\$ 1.25$ to $\$ 2.00$. Five libraries reported stamps were acceptable as payment for charges of $\$ 1.00$ or less, and one will accept stamps to the amount of $\$ 2.00$. Sixteen do their own billing and collecting of charges; two delegate this task to the university business office. Two allow borrowing libraries to set up a deposit fund from which the lending library draws to cover the cost of photocopies. At one library the borrowing library must purchase coupons in advance which it then uses to pay for the photocopies. Finally, eight libraries indicated that the procedure followed for supplying photocopies of requests that originated as interlibrary loans differed from that 
followed for regular photoduplication requests. These figures, although they represent less than half the libraries supplying photocopies in lieu of loans, give some indication of the wide variation in procedure followed by the libraries.

The survey shows a trend toward greater restrictions on the loan of serial publications together with an increase in the substitution of photocopy. This may be due to the fact that the wealth of material being published daily makes it impossible for any one library to contain a high percentage of the resources its researchers will need to consult. Moreover, the number of graduate students and other researchers is rapidly increasing. With the development of inexpensive and rapid methods of photocopying it is possible for libraries to keep research materials where they are available to their own students and faculty and at the same time enable them to meet the growing demands from other libraries for materials.

\section{Association of Research Libraries}

The 63rd meeting of the Association of Research Libraries was convoked at 2 P.M. on Sunday, January 26, at the Edgewater Beach Hotel in Chicago. The topic of the afternoon session was "Operations Research in Large Libraries." Philip Morse, professor of physics and director of the Operations Research Center at Massachusetts Institute of Technology, pointed out how a mathematical model of a library can be one more source of guidance than has been available in the past to a library manager who must make a decision. Robert Roy Hall, dean of the school of engineering science at the Johns Hopkins University reported upon a study in that institution of prospects for mechanizing circulation control and for utilizing computers to predict growth rates, to identify volumes for retirement, and to indicate titles of which more copies are needed. Warren J. Haas, associate director of the Columbia University libraries, described SCUL - or, Simulation of the Columbia University Libraries. A mathematical model now between 8 and 10 per cent complete, SCUL is expected to aid in determining for that system an optimum level of user satisfaction for the money spent upon library service. Vigorous discussion ensued.

In the evening session it was announced that the Linda Hall and Huntington libraries had accepted invitations to membership in ARL. Edward G. Freehafer (NYPL) was elected vice chairman and chairman-elect, and G. Flint Purdy (Wayne) and William Locke (MIT) were elected to the board of directors. It was voted that the association should devote priority attention to increasing centralization of the nation's cataloging effort. Two grants were announced-both from CLR-one to fund a conclave on the acquisition of Africana, and another to enlarge the Farmington Plan Newsletter. John Cronin (Library of Congress) described problems relative to LC's catalog search service and to its circulation of lists of books not located in NUC. Gordon Williams (Midwest Inter Library Center) reported progress in efforts to see the pre-1952 NUC in print. The Librarian of Congress invited attention to the study of Automation and the Library of Congress and requested response from the membership. Reports were heard from several committees which had not filed written reports or which needed to alter or amend previously filed reports, and the meeting was adjourned at 10:30 P.M.-D.K. 